\title{
Extreme values of snow-related variables in Mediterranean regions: trends and long-term forecasting in Sierra Nevada (Spain)
}

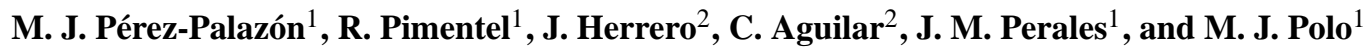 \\ ${ }^{1}$ Fluvial Dynamics and Hydrology-Andalusian Institute of Earth System Research, University of Cordoba, \\ Cordoba, Spain \\ ${ }^{2}$ Fluvial Dynamics and Hydrology-Andalusian Institute of Earth System Research, University of Granada, \\ Granada, Spain
}

Correspondence to: M. J. Pérez-Palazón (mj.perez@uco.es)

Received: 21 April 2015 - Accepted: 21 April 2015 - Published: 11 June 2015

\begin{abstract}
Mountain areas in Mediterranean regions constitute key monitoring points for climate variability and its impacts, but long time datasets are not always available due to the difficult access to high areas, relevant for capturing temperature and precipitation regimes, and the predominance of cloudy remote sensing images during the snow season. Sierra Nevada National Park (South Spain), with altitudes higher than $3500 \mathrm{~m}$ a.s.l., is part of the Global Change in Mountain Regions network. Snow occurrence just $40 \mathrm{~km}$ from the seaside determines a wide range of biodiversity, a snowmelt fluvial regime, and the associated ecosystem services. This work presents the local trend analysis of weather variables at this area together with additional snow-related variables. For this, long term point and distributed observations from weather stations and remote sensing sources were studied and used as input and calibration datasets of a physically based snow model to derive long term series of mean and maximum daily fraction of snow covered area, annual number of days with snow, annual number of days with precipitation, mean and maximum mean daily snow water equivalent, and snowmelt and evaporation volumes. The joint analysis of weather and snow variables showed a decrease trend in the persistence and extent of the snow cover area. The precipitation regime, rather than the temperature trend, seems to be the most relevant driver on the snow regime forcing in Mediterranean areas. This poses a constraint for rigorous scenario analysis in these regions, since the precipitation pattern is poorly approximated by climatic models in these regions.
\end{abstract}

\section{Introduction}

Climate variability impact on the hydrological regime is more evident over mountain regions due their particular extreme conditions (Beniston, 2003; IPCC, 2007). Hence, a continuous monitoring of snow state variables can help to assess climate variability and early detection of shifts at significant time scales. For example, the decrease of snow cover area is an indicator of a warming climate phase conditions. Moreover, in regions where the typical alpine-mountain climate is modified by additional meteorological drivers(i.e. the recurrence of drought periods and torrential rainfall events), these impacts are enhanced, which makes them crucial areas to monitor these climate variations. This is the case of
Mediterranean mountainous areas, where alpine and semiarid conditions coexist (Giorgi, 2006).

However, snow monitoring constitutes arduous work. On one hand, the limited accessibility to these sites during the snow season, and the hard working conditions for the instrumentation, make in situ continuous monitoring systems difficult to maintain (De Walle and Rango, 2008). On the other hand, the potential use of satellite remote sensing information (i.e. Landsat TM, ETM+ and OLI with temporal resolution of 16 days and spatial resolution of $30 \mathrm{~m} \times 30 \mathrm{~m}$, MODIS, daily images with $250 \mathrm{~m} \times 250 \mathrm{~m}$ spatial resolution, and NOAA, $1 \mathrm{~km} \times 1 \mathrm{~km}$ daily images) to capture snow evolution at medium and large scales is limited to recent decades, poses a constraint for snow applications in heterogeneous ar- 
eas due to their fixed and not always high enough spatial resolution, and is not feasible during a significant fraction of the snow season because of the recurrent presence of cloud cover. Therefore, a lack of detailed snow information is common over mountainous areas, especially at high altitudes.

The use of physically based snowmelt-accumulation model, locally calibrated and validated by means of remotely sensed data, allows estimating the snowpack evolution and its significant state variables during these gap periods, over the non-monitored areas, and beyond the snow monitoring period (Pimentel et al., 2015). For that, a correct representation of the meteorological forcings, the main inputs in snow modelling, is crucial to obtain accurate snow simulations, the weather data series available in the study area, and their quality, being a relevant limitation for a satisfactory model performance. Weather variables long-term series can, thus, be used to generate long-term snow-related variables series, which allows the understanding of the past snow dynamics, and its uncertainty, the estimation of future trends, and the forecasting of snow behaviour under given climatic scenarios. The objective of this work is to study the meteorological patterns in Sierra Nevada Mountain, an alpine climate region in Southern Spain, in relation to selected snow-related variables to obtain long-term trends in this area as a basis to assess future climate scenarios. Special emphasis has been done in the analysis of the occurrence of extreme events and its impact on snow dynamics.

\section{Study site and available data}

Sierra Nevada Mountains, in Southern Spain, are a linear mountainous range parallel to the shoreline of the Mediterranean Sea (Fig. 1), where the highest summits of the Iberian Peninsula can be found (Mulhacen peak, $3479 \mathrm{~m}$ ). It is the second highest range in Europe, only surpassed by the Alps. Consequently, snow usually appears throughout the year in the areas above $2000 \mathrm{~m}$. Its proximity to the sea, only $40 \mathrm{~km}$ south, generates a very specific climate as the result of the interaction between sea and mountain conditions. The typical alpine climate is then modified by the Mediterranean surrounding features and, thus, snow is significantly affected. Annual precipitation fluctuates widely and can range from 300 to $1000 \mathrm{~mm}$, with a high spatial variability throughout the area due to topographic effects. The average temperature ranges from -5 to $5{ }^{\circ} \mathrm{C}$ during the snow season, although minimum values of $-20^{\circ} \mathrm{C}$ can be found at certain times in winter. Due to these particular conditions, it belongs to the Global Change in Mountain Regions network (GLOCHAMORE) and it is recognizes as both Natural and National Parks.

Different weather station networks are available in this area, lacking, in general, data over $2000 \mathrm{~m}$ a.s.l.; in this work, validated daily datasets of precipitation, temperature, wind velocity, and relative humidity from selected stations

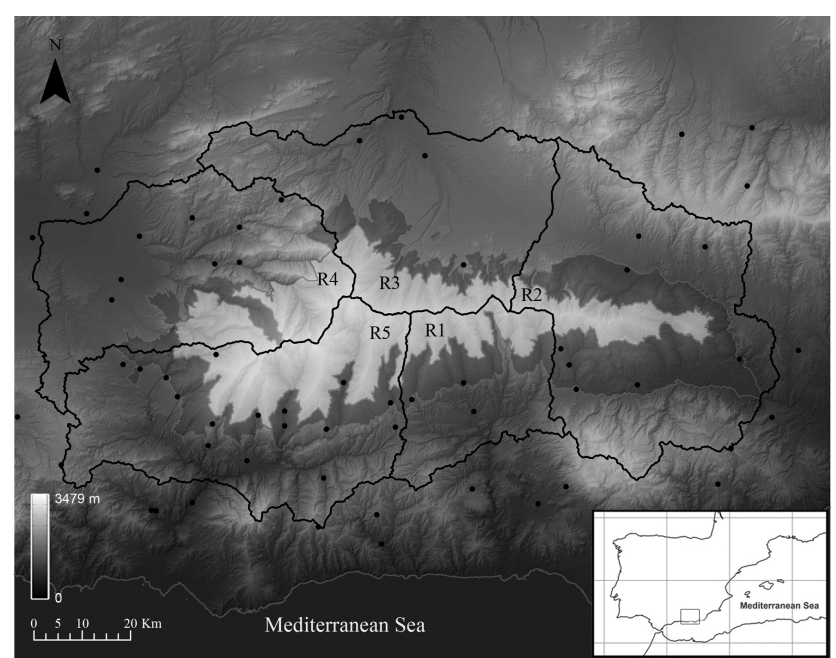

Figure 1. Location of Sierra Nevada Mountain Range in Spain; limits of the protected areas: National Park (dark grey coloured area) and Natural Park (light grey coloured area); location of the different weather station (black dots); and limits of the five regions in which the study area has been divided: R1 - Adra, R2 - Andarax, R3 Fardes, R4 - Genil and R5 - Guadalfeo.

of the Spanish Meteorological Agency (AEMET) were employed as input of a distributed physically based snow model (Fig. 1), calibrated and validated in this region in previous works (Herrero et al., 2010; Pimentel et al., 2014; PérezPalazón et al., 2014). The reference period 1960-2000 was analysed for long-term trends and basis of future scenarios assessment. The study is limited to area in which five different regions were identified to assess the local impact of weather trends on snow (Fig. 1).

\section{Methods}

The average annual precipitation and mean, maximum and minimum average daily temperature for the reference period, 1960-2000, were obtained over the study area in Sierra Nevada, together with selected annual snow related-variables that were simulated during this period using the physical and distributed hydrological model, WiMMed (Herrero et al., 2011; http://www.ugr.es/ herrero/wimmed/), developed and calibrated in this region (Herrero et al., 2009, 2011; Millares et al., 2009; Aguilar et al., 2010; Aguilar and Polo, 2011; Pimentel et al., 2014). The model includes specific spatial interpolation algorithms for the weather variables to include the abrupt topography of this area (Herrero et al., 2010), and an energy and water balance snow model. Long-term trends of both the meteorological and snowrelated variables were analysed emphasizing the importance of extreme precipitation events. 


\subsection{Snow modelling}

The snowmelt-accumulation model for Mediterranean sites developed by Herrero et al. (2009) is a physical model based on a point mass and energy balance, which is extended to a distributed way by means of depletion curves (Herrero et al., 2011; Pimentel et al., 2014).

The model assumes a horizontally uniform snow cover distributed in one vertical layer. In the control volume defined by the snow column per unit area, which has the atmosphere as an upper boundary and the ground as a lower one, the water mass and energy balance can be expressed by:

$$
\begin{aligned}
\frac{\mathrm{d} S W E}{\mathrm{~d} t}=R-E+W-M & \\
\frac{\mathrm{d}(S W E \cdot u)}{\mathrm{d} t}=\frac{\mathrm{d} U}{\mathrm{~d} t}= & K+L+H+G+R \cdot u_{\mathrm{R}}-E \cdot u_{\mathrm{E}} \\
& +W \cdot u_{\mathrm{W}}-M \cdot u_{\mathrm{M}},
\end{aligned}
$$

where SWE (snow water equivalent) is the water mass in the snow column, and $u$ is the internal energy per unit of mass ( $U$ for total internal energy). In the mass balance, $R$ defines the precipitation rate; $E$ is water vapour diffusion rate (evaporation/condensation); $W$ represents the mass transport rate due to wind; and $M$ is the melting water rate. On the other hand, regarding energy fluxes, $K$ is the solar or short wave radiation; $L$ the thermal or long-wave radiation; $H$ the exchange of sensible heat with the atmosphere rate; $G$ the heat exchange with the soil rate; and $u_{\mathrm{R}}, u_{\mathrm{E}}, u_{\mathrm{W}}$ and $u_{\mathrm{M}}$ are the advective heat rate terms associated with each one of the mass fluxes involved in Eq. (1).

This approach permits an easy extension to a distributed model by means of making calculations simultaneously in each cell. However, a direct extension cannot be done when the cell area is not completely covered by snow. In such cases, the parameterization of subgrid processes is made by including depletion curves (Luce and Tarboton, 2004; Herrero et al., 2010; Pimentel et al., 2014).

The point model was calibrated and validated by means of local in situ measurements (Herrero et al., 2009) and the distibuted model thanks to remote sensing information (Herrero et al., 2010; Pimentel et al., 2014).

\subsection{Long term data analysis}

Annual and decadal regimes for the reference 40-year period (1960-2000) were analysed for the average annual precipitation $(P)$ and mean, maximum and minimum average daily temperature $\left(T_{\text {mean }}, T_{\max }, T_{\min }\right)$ in the area, obtained from daily measurements at the selected weather stations, and the following snow related variables obtained from the validated snow model: (1) mean and maximum daily fraction of snow covered area $\left(\mathrm{SC}_{\text {mean }}\right.$ and $\left.\mathrm{SC}_{\max }\right)$, obtained as mean and maximum value of daily percentage of snow covered area over the whole area $\left(\mathrm{m}^{2} \mathrm{~m}^{-2}\right)$; (2) annual number of days with snow ( $\left.n_{\text {day with snow }}\right)$, calculated as the number of day in which the snow exceeds 10 th percentile of $\mathrm{SC}_{\text {mean }}$ distribution (days); (3) annual number of days with precipitation ( $n_{\text {day }}$ with precipitation $)$, counted as days with precipitation greater than $1 \mathrm{~mm} \mathrm{day}^{-1}$ (days); and (4) mean and maximum mean daily snow water equivalent $\left(\mathrm{SWE}_{\text {mean }}\right.$ and $\left.\mathrm{SWE}_{\max }\right)$, calculated as mean and maximum values of daily average SWE (mm). Their individual temporal trend and main statistic descriptors were performed. The significance of these temporal trends was tested by means of Mann-Kendall test (Gibbons and Chakraborti, 2010). The test assumes as null hypothesis: non-monotonic trend $\left(H_{0}\right)$, which was tested versus the alternative hypothesis: presence of monotonic trend $\left(H_{1}\right)$. A level of significance $(\alpha)$ equal to 0.05 is used to define the rejection region. The snow regime dependence on weather variables was also assessed.

\subsection{Extreme data analysis}

The extreme data analysis was performed on a precipitation event definition basis. A precipitation event is defined as a period in which rainfall over $1 \mathrm{~mm} \mathrm{day}^{-1}$ is registered at some weather station within the study area (Polo et al., 2010). The event is characterized by two main variables: $D$, duration (days) and $P_{\text {event }}$, cumulative precipitation over the study area $(\mathrm{mm})$. Different snow variables selected from the long term analysis results were also obtained for each event in the resulting 40-year event series at the region. The extreme data analysis was done on the subset events over the 95th percentile of $P_{\text {event }}$.

\section{Results}

This section shows the different results of the long-term and extreme data analysis performed over selected annual and decadal variables, average over the study area $\left(4584 \mathrm{~km}^{2}\right)$. The distribution over the five identified regions in the area (Fig. 1) is also presented to further asses some of the results.

\subsection{Long term data analysis}

\subsubsection{Average annual precipitation and temperature during 1960-2000}

On a regional basis, the 40-year mean annual values of $P$ and $T$ are 510 and 93 mm year $^{-1}$, for the total precipitation and snowfall, respectively, and $26,12.5$ and $0.4{ }^{\circ} \mathrm{C}$ for the average daily maximum, mean and minimum temperature, respectively. Figure $2 \mathrm{a}$ and $\mathrm{b}$ show the evolution during the reference period (1960-2000) of the annual precipitation (total precipitation and snowfall) and the maximum, mean and minimum daily temperature averaged over the study area by the model from the available daily datasets measured at the weather stations in Fig. 1. The decadal trend for these variables has also been included (Fig. 2c, d). 

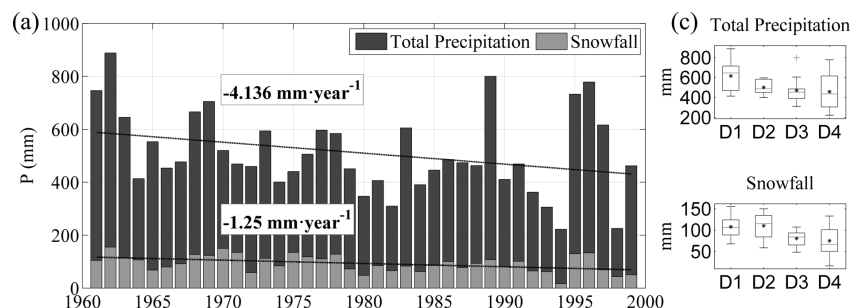

(b)
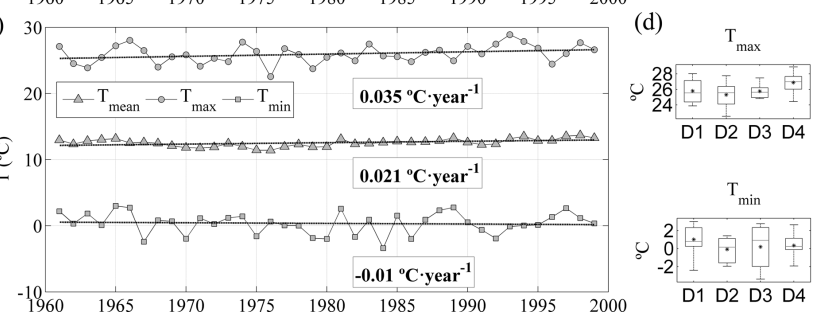

Figure 2. Evolution of the annual cumulative precipitation (a) and the annual mean, maximum and minimum daily temperature (b), averaged over the study area. Boxplot of the decadal mean annual cumulative precipitation (c) and the decadal mean maximum, mean and minimum daily temperature (d); the central mark represents the median, the upper and lower edges of the box are the 25th and 75th percentiles, respectively, the whiskers extends to the most extreme data point not considered outlier, crosses are the outliers, and dots represent the decadal mean values.

Globally decreasing annual rates were obtained for both the total precipitation and snowfall (Fig. 2a), with values of 4.136 and $1.250 \mathrm{~mm}$ year $^{-1}$, respectively. Their decadal cumulative values analysis (Fig. 2c) shows the same trend, with snowfall dropping from $108 \mathrm{~mm}^{-1} \mathrm{yr}^{-1}$ in the first decade to the final decadal $75 \mathrm{~mm}$ year ${ }^{-1}$. A greater dispersion of both annual variables can be observed in this last decade.

In the case of temperature, an increasing trend of the annual mean of the daily mean and maximum values was found (Fig. 2c), with global rates of 0.035 and $0.021{ }^{\circ} \mathrm{Cyear}^{-1}$, respectively. On the contrary, a decreasing global rate of $0.009^{\circ} \mathrm{C}_{\text {year }}{ }^{-1}$ can be observed in the minimum values. The same trends were found in the decadal analysis (Fig. 2d), without any clear pattern in the dispersion of the annual values for each decade.

\subsubsection{Snow-related variables}

The evolution of $\mathrm{SC}_{\text {mean }}$ and $\mathrm{SC}_{\max }$ at the study region is represented in Fig. 3a, which 40-year means values are 0.055 and $0.38 \mathrm{~m}^{2} \mathrm{~m}^{-2}$, corresponding with areas of 254.02 and $1736.50 \mathrm{~km}^{2}$, respectively. A decreasing trend is found for the mean value $\left(0.0007 \mathrm{~m}^{2} \mathrm{~m}^{-2}\right.$ year $\left.^{-1}\right)$ against the growing trend found in the case of the maximum value trend $\left(0.0007 \mathrm{~m}^{2} \mathrm{~m}^{-2}\right.$ year $\left.{ }^{-1}\right)$. Figure $3 \mathrm{~b}$ and $\mathrm{c}$ show the decadal analysis for both variables; where similar trends are also observed, with values over 0.35 and between 0.05 and 0.06 for the decadal $\mathrm{SC}_{\max }$ and $\mathrm{SC}_{\min }$, respectively. Nevertheless, a high dispersion is found between decades.

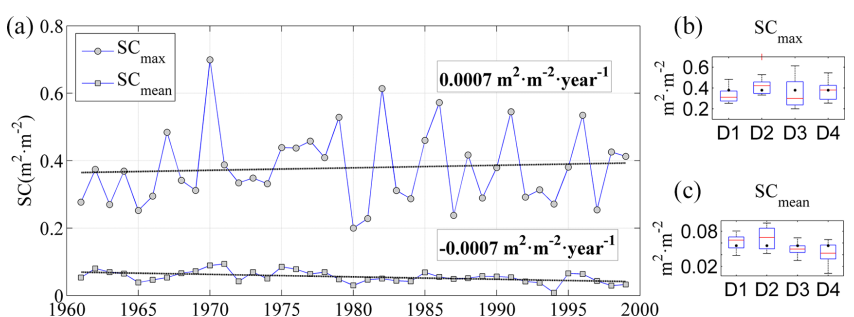

Figure 3. Evolution of the annual mean and maximum daily fraction of snow covered area over the whole study area (a). Boxplot of the decadal maximum (b) and mean (c) daily fraction of snow covered area; the central mark represents the median, the upper and lower edges of the box are the 25 th and 75 th percentiles, respectively, the whiskers extends to the most extreme data point not considered outlier, crosses are the outliers, and dots represent the decadal mean values.

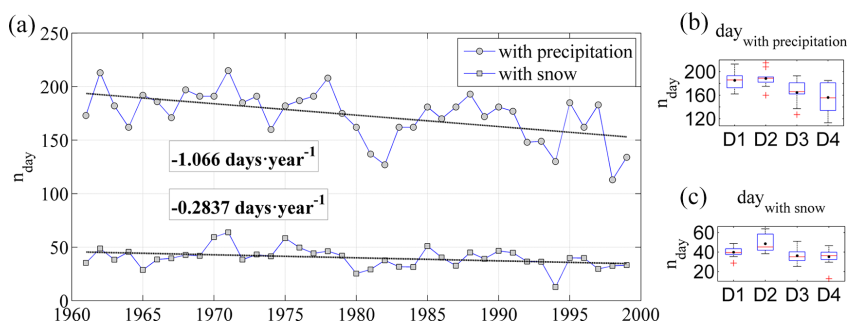

Figure 4. Evolution of the annual number of days with snow and with precipitation over the whole study area (a). Boxplot of the days with precipitation (b) and the days with snow (c); the central mark represents the median, the upper and lower edges of the box are the 25th and 75th percentiles, respectively, the whiskers extends to the most extreme data point not considered outlier, crosses are the outliers, and dots represent the decadal mean values.

Figure 4a includes the evolution of the annual number of days with precipitation and with snow over the whole study area. Mean 40-year values of 173 and 40 days are found respectively. Both variables experiment a global decreasing trend, which represents a loss of 42 days with precipitation and 11 days with snow over the area during the analysed period. Figure $4 \mathrm{~b}$ and $\mathrm{c}$ also show decreasing trend with variable dispersion between decades, which for example is very high in the last decades for days with precipitation.

The evolution of the annual mean of the maximum and mean daily SWE values is represented in Fig. 5a, in which a high variability can be observed, with mean 40 -year values of 38.73 and $10.91 \mathrm{~mm}$, respectively. The global decreasing trend obtained for both variables is higher for $\mathrm{SWE}_{\max }$, which doubles the rate obtained for the $\mathrm{SWE}_{\text {mean }}(0.625$ against $0.235 \mathrm{~mm} \mathrm{year}^{-1}$ ). The boxplots (Fig. 5b, c) with the decadal analysis also shows decreasing trends, with a high dispersion in both the first and last decades; this last decade shows the highest value for the $\mathrm{SWE}_{\max }$ in the reference period, and the widest interval of values for both $\mathrm{SWE}_{\max }$ and $\mathrm{SWE}_{\text {mean }}$ variables. 

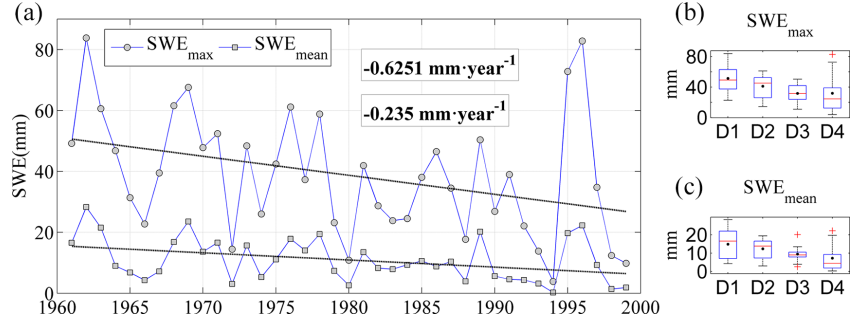

Figure 5. Evolution of the annual mean of the maximum and mean daily SWE over the study area (a). Boxplot of the decadal maximum (b) and mean (c) daily SWE; the central mark represents the median, the upper and lower edges of the box are the 25 th and 75 th percentiles, respectively, the whiskers extends to the most extreme data point not considered outlier, crosses are the outliers, and dots represent the decadal mean values.

\subsection{Extreme data analysis}

Following the extreme event definition in Sect. 3, 82 extreme precipitation events were identified during the reference period, with a mean duration and cumulative precipitation of 12 days event $^{-1}$ and $120 \mathrm{mmevent}^{-1}$. Figure 6a shows the evolution of the annual number of extreme events throughout the study period, with a mean value of 2.1 events year $^{-1}$ in a range of $0-5$ events year ${ }^{-1}$. The relation between the annual cumulative precipitation associated to extreme events and the annual cumulative precipitation for each year is included in Fig. 6b; again, a globally decreasing rate was found $\left(0.006 \mathrm{~mm} \mathrm{~mm}^{-1}\right.$ year $\left.^{-1}\right)$. Finally, the torrential nature of these events can be analysed from Fig. 6c quantifying the rainfall intensity for the extreme event per year; a global increasing trend is found of $0.061 \mathrm{~mm} \mathrm{day}^{-1}$.

\section{Discussion}

The Mann-Kendall test performed to assess the significance of the trend shows that only the trends found for, $P$, snowfall, $T_{\text {mean }}, \mathrm{SC}_{\text {mean }}, n_{\text {day with precipitation }}, \mathrm{SWE}_{\max }$ and $\mathrm{SWE}_{\text {mean }}$ are statistically significant (Table 1).

The results show a clear decrease of the annual snowfall on a regional basis $\left(-1.25 \mathrm{mmyear}^{-1}\right)$, which is also reflected in a reduction of the annual mean SWE $\left(0.23 \mathrm{~mm}\right.$ year $\left.^{-1}\right)$.Therefore, the shift in the precipitation regime seems to be the most determining driver of the snow variables annual trends. The annual snowfall correlates linearly with $P\left(r^{2}=0.50\right)$, but this correlation is very poor with $T_{\text {mean }}\left(r^{2}=0.18\right)$, although some increasing trend could be observed with decreasing annual mean daily maximum temperature values. This behaviour differs from the trends observed in the Alps, where precipitation and snow trends have opposing trends and seem to be more related with temperature regime (Laternser and Schneebeli, 2003). The annual fraction of snowfall over the total precipitation in the study
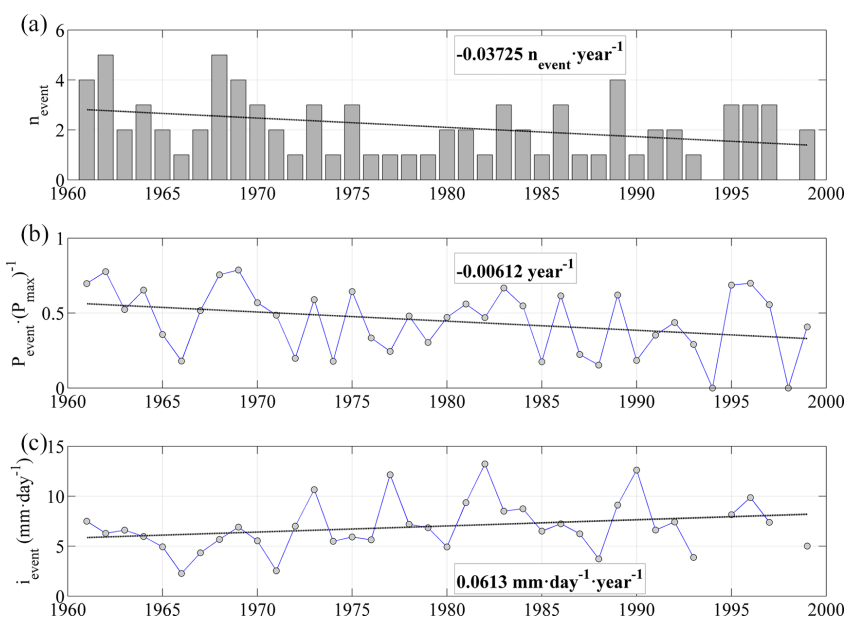

Figure 6. Annual evolution of the number of extreme event in the 40 -year study period (a); relation between annual cumulative precipitation associated with extreme events and the annual cumulative total precipitation (b); and intensity for the extreme events (c).

Table 1. Results of Mann-Kendall test with a level of significance $\alpha=0.05$ realized for each one of the variables analyzed to evaluate the significance of the trends found.

\begin{tabular}{lrl}
\hline $\begin{array}{l}\text { Variable } \\
\text { analyzed }\end{array}$ & $\begin{array}{r}\text { Mann-Kendall } \\
\text { test statistic }\end{array}$ & $\begin{array}{l}\text { Test } \\
\text { interpretation }\end{array}$ \\
\hline$P$ & 2.129 & Reject $H_{0}$ \\
Snowfall & 2.613 & Reject $H_{0}$ \\
$T_{\max }$ & -1.863 & No reject $H_{0}$ \\
$T_{\operatorname{med}}$ & -2.710 & Reject $H_{0}$ \\
$T_{\min }$ & 0.605 & No reject $H_{0}$ \\
$\mathrm{SC}_{\max }$ & -0.702 & No reject $H_{0}$ \\
$\mathrm{SC}_{\operatorname{mean}}$ & 2.806 & Reject $H_{0}$ \\
$n_{\text {day with precipitation }}$ & 1.718 & Reject $H_{0}$ \\
$n_{\text {day with snow }}$ & 2.564 & No reject $H_{0}$ \\
$\mathrm{SWE}_{\max }$ & 2.444 & Reject $H_{0}$ \\
SWE $_{\text {mean }}$ & 1.808 & Reject $H_{0}$ \\
$n_{\text {event }}$ & 1.924 & No reject $H_{0}$ \\
$P_{\text {event }}\left(P_{\text {max }}\right)^{-1}$ & -1.536 & No reject $H_{0}$ \\
$I_{\text {event }}$ & 3.043 & No reject $H_{0}$ \\
\hline
\end{tabular}

area does not directly correlate with any of the weather variables analysed in this work.

The annual mean of $\mathrm{SWE}_{\max }$ experiments a higher decrease than the daily $\mathrm{SWE}_{\text {mean }}$ value. Nevertheless, this is not accompanied by a great reduction in the annual mean of the maximum snow covered area. Thus, an average regional reduction in the thickness of the snowpack must be associated to these peak moments, which supports the precipitation regime being the main responsible of the snow dynamics over this reference period.

The torrential events are more common in the last decades, as the intensity of the extreme events showed. This is also appreciable in the greater dispersion associated to the extreme 
events variables found when compared to most of the variables during this last decade. The non-linearity of the snow behaviour makes it necessary a sound modelling of these regions if future scenarios assessment is to be performed.

During this reference period, a global decrease in the annual precipitation rate and an increase in the annual mean temperature values has been quantified. The dataset of temperature and precipitation downscaling for the different IPCC scenarios over the study area for this reference period (19602000) overestimate both the precipitation and temperature annual rates of decrease and increase to $-2.1 \mathrm{~mm}$ year $^{-1}$ and $0.03^{\circ} \mathrm{C}$, and thus fail to reproduce the measured values. The direct use of these projected data sets is never advisable but for snow regions must be made with extreme caution. The combination of long term weather variables observations and snow modelling constitutes a sound alternative for historical time series trends over mountainous areas and is an adequate basis for correcting and simulating future scenario projections.

\section{Conclusions}

The joint analysis of weather and snow variables showed a decrease trend in the extent and persistence of the snow covered area over Sierra Nevada range. The precipitation rather than the temperature regime seems to be the most relevant driver on the snow regime forcing in Mediterranean areas over the reference period (1960-2000). This poses a constraint for rigorous scenario analysis in these regions, since the precipitation pattern is poorly approximated by climatic models in these regions and further assessment by means of a sound snow modelling is required.

Acknowledgements. This work has been supported by the Spanish Ministry of Agriculture, Food and Environment (Biodiversity Foundation, Project "Study of the effect of global change on snow and high mountain hydrology in Sierra Nevada National Park") and the Spanish Ministry of Science and Innovation (Research Project CGL 2011-25632, "Snow dynamics in Mediterranean regions and its modelling at different scales. Implications for water management"). Moreover the present work was partially developed within the framework of the Panta Rhei Research Initiative of the International Association of Hydrological Sciences (IAHS) (Working Group Water and energy fluxes in a changing environment). Finally, we thank the support provided by the National and Natural Park of Sierra Nevada.

\section{References}

Aguilar, C. and Polo, M. J.: Generating reference evapotranspiration surfaces from the Hargreaves equation at watershed scale, Hydrol. Earth Syst. Sci., 15, 2495-2508, doi:10.5194/hess-152495-2011, 2011.

Aguilar, C., Herrero, J., and Polo, M. J.: Topographic effects on solar radiation distribution in mountainous watersheds and their influence on reference evapotranspiration estimates at watershed scale, Hydrol. Earth Syst. Sci., 14, 2479-2494, doi:10.5194/hess14-2479-2010, 2010.

Beniston, M.: Climatic change in mountain regions: a review of possible impacts, Climate Change, 59, 5-31, 2003.

DeWalle, D. and Rango, A.: Principles of snow hydrology, Cambridge University Press, Cambridge, UK, 428 pp., 2008.

Gibbons, J. D. and Chakraborti, S.: Nonparametric statistical inference, Taylor \& Francis/CRC Press, Boca Raton, USA, 2010.

Giorgi, F.: Climate change hot-spots, Geophys. Res. Lett., 33, L08707, doi:10.1029/2006GL025734, 2006.

Herrero, J., Polo, M. J., Moñino, A., and, Losada, M. A.: An energy balance snowmelt model in a Mediterranean site, J. Hydrol., 371, 98-107, 2009.

Herrero, J., Aguilar, C., Polo, M. J., and Losada, M. A.: Mapping of meteorological variables for runoff generation forecast in distributed hydrological modeling, Proceeding Hydraulic Measurements and Experimental Methods, New York, 606-611, 2010.

Herrero, J., Polo, M. J., and Losada, M. A.: Snow evolution in Sierra Nevada (Spain) from an energy balance model validated with Landsat TM data, Proceedings SPIE 8531, Remote Sensing for Agriculture, Ecosystems, and Hydrology XIV, Prague, Czech Republic, 2011.

IPCC: Climate Change 2007: Synthesis Report, Contribution of Working Groups I, II and III to the Fourth Assessment Report of the Intergovernmental Panel on Climate Change, Core Writing Team, Pachauri, R. K, and Reisinger, A. (Eds.), IPCC, Geneva, Switzerland, 104 pp., 2007.

Laternser, M. and Schneebeli, M.: Long-term snow climate trends snow climate trends of the Swiss Alps (1931-99), Int. J. Climatol., 23, 733-750, 2003.

Luce, C. H. and Tarboton, D. G.: The application of depletion curves for parameterization of subgrid variability of snow, Hydrol. Process., 18, 1409-1422, 2004.

Millares, A., Polo, M. J., and Losada, M. A.: The hydrological response of baseflow in fractured mountain areas, Hydrol. Earth Syst. Sci., 13, 1261-1271, doi:10.5194/hess-13-12612009, 2009.

Pérez-Palazón, M. J., Pimentel, R., Herrero, J., and Polo, M. J.: Analysis of snow spatial and temporary variability through the study of terrestrial photography in the Trevelez river valley, Proceedings SPIE 8531, Remote Sensing for Agriculture, Ecosystems, and Hydrology XIV, Edimburgh, 2014.

Pimentel, R., Herrero, J., and Polo, M. J.: Snow in a semiarid mountainous area combining snow modelling and Landsat spectral mixture analysis, Proceeding RSHS14 and ICGRHWE14, Guangzhou, China, 2014.

Pimentel, R., Herrero, J., Zeng, Y., Su, Z., and Polo, M. J.: Study snow dynamics at subgrid scale in semiarid environment combining terrestrial photography data assimilation techniques, J. Hydrometeorol., 16, 563-578, doi:10.1175/JHM-D14-0046.1, 2015.

Polo, M. J., Herrero, J., Aguilar, C., Millares, A., Moñino, A., Nieto, S., and Losada, M. A.: WiMMed a distributed physically based watershed model I: Description and validation, in: Environmental Hydraulics - Theoretical, Experimental and Computational Solutions, CRC Press, Taylor and Francis, 360 pp., 2010. 